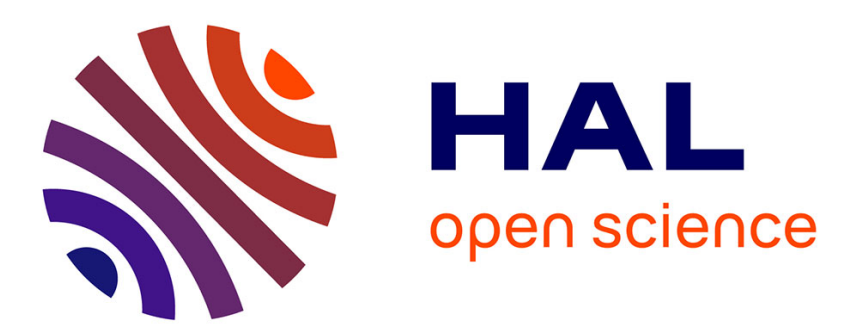

\title{
UV-Induced Structural Changes of Model DNA Helices Probed by Optical Spectroscopy
}

A. Bányász, S. Karpati, E. Lazzarotto, D. Markovitsi, Thierry Douki

\section{To cite this version:}

A. Bányász, S. Karpati, E. Lazzarotto, D. Markovitsi, Thierry Douki. UV-Induced Structural Changes of Model DNA Helices Probed by Optical Spectroscopy. Journal of Physical Chemistry C, 2009, 113 (27), pp.11747-11750. 10.1021/jp901841s . hal-00404379

\section{HAL Id: hal-00404379 \\ https://hal.science/hal-00404379}

Submitted on 16 Jul 2009

HAL is a multi-disciplinary open access archive for the deposit and dissemination of scientific research documents, whether they are published or not. The documents may come from teaching and research institutions in France or abroad, or from public or private research centers.
L'archive ouverte pluridisciplinaire HAL, est destinée au dépôt et à la diffusion de documents scientifiques de niveau recherche, publiés ou non, émanant des établissements d'enseignement et de recherche français ou étrangers, des laboratoires publics ou privés. 


\title{
UV-induced structural changes of model DNA helices
}

\section{probed by optical spectroscopy}

\author{
Akos Banyasz, Szilvia Karpati, Elodie Lazzarotto, Dimitra Markovitsi* \\ Laboratoire Francis Perrin, CEA/DSMIRAMIS/SPAM - CNRS URA 2453, CEA/Saclay, 91191 \\ Gif-sur-Yvette, France
}

Thierry Douki

Laboratoire des Lésions des Acides Nucléiques CEA/DSM/INAC/SCIB - UJC UMR E 3

CEA/Grenoble, 38054 Grenoble, France

\begin{abstract}
Chemical alterations of DNA, if not repaired, may lead to carcinogenic mutations. Structural modifications of the helix around the lesion enable its recognition by repair enzymes. We have used absorption spectroscopy and mass spectrometry to detect structural changes provoked by cyclobutane thymine dimers, the major lesion induced by UV radiation. We found that formation of a cyclobutane dimer in the model duplex $(\mathrm{dA})_{20} .(\mathrm{dT})_{20}$ destroys base stacking on the adenine strand. The physical background of this novel approach is the existence of charge transfer states among neighboring bases whose contribution to the hypochromism of the helix disappears following destacking.
\end{abstract}




\section{Introduction}

Ultraviolet radiation absorbed by DNA is known to trigger chemical reactions which may lead to mutations and ultimately to skin cancer. ${ }^{1}$ Fortunately, most of these lesions are repaired by the cell machinery. Repair enzymes are likely to recognize the damaged region because it acquires specific structural features. As cyclobutane pyrimidine dimers (CPDs) formed between adjacent thymines are the predominant $\mathrm{UV}$-induced lesions, ${ }^{2}$ understanding the structural changes provoked by their formation is a major issue and an important challenge. The solution structure of CPD containing duplexes was studied by various methods, such as NMR, gel electrophoresis, fluorescence energy transfer and molecular dynamic simulations. ${ }^{3-10}$ The conclusions emerging from these investigations converge toward a picture where the presence of a CPD mainly affects the structure of the sites located very close to it. An important perturbation which was not evidenced so far is local denaturation, e.g. transformation of the double strand to two single strands increasing the probability for an adenine opposite to the CPD to flip out (Figure 1).

Figure 1

It has been known for a long time that denaturation of DNA duplexes caused by heating leads to an increase in their capacity to absorb light around $260 \mathrm{~nm}$. Thus, if local denaturation does occur following UV irradiation, its fingerprint should be detectable in the absorption spectra. We show here that this may happen indeed by studying the duplex $(\mathrm{dA})_{20} .(\mathrm{dT})_{20}$. We have chosen such a simple base sequence, because its excited states have been the subject of recent experimental ${ }^{11-15}$ and theoretical studies. ${ }^{16}$ For comparison, we also examine the single strand $(\mathrm{dT})_{20}$. 
In practice, solutions of $(\mathrm{dA})_{20} \cdot(\mathrm{dT})_{20}$ in phosphate buffer were exposed to continuous irradiation at $266 \mathrm{~nm}$. The yield of the photoproducts was then determined using high performance liquid chromatography coupled to mass spectrometry following enzymatic digestion. ${ }^{17}$ Damaged region spectra were obtained by subtracting the spectra recorded before irradiation from those recorded after; such a procedure is inspired by time-resolved absorption measurement used to determine the dynamics of thymine dimer formation. ${ }^{18}$ As absorbance changes are very weak, of the order of $10^{-3}$, a delicate control of the experimental conditions is required for their detection. A key point of our method is the comparison of the absorption features of the same solution before and after irradiation which minimizes the experimental errors. The method consisting of comparing the UV spectrum of unmodified oligonucleotides with that of CPD containing helices prepared by solid state synthesis, as used, for example, in the case of NMR studies, ${ }^{5}$ was precluded because the required accuracy in purity and concentration of the solutions seems very unlikely to reach.

\section{Experimental Details}

Oligomers were purchased from Eurogentec. Single strands were lyophilized whereas $(\mathrm{dA})_{20} .(\mathrm{dT})_{20}$ was provided after PAGE purification, as a double strand in phosphate buffer $\left(\mathrm{pH}=6.8 ; 0.1 \mathrm{M} \mathrm{NaH}_{2} \mathrm{PO}_{4}, 0.1 \mathrm{M} \mathrm{Na}_{2} \mathrm{HPO}_{4}, 0.25 \mathrm{M} \mathrm{NaCl}\right)$. For each oligomer a dozen of different batches were used to check the reproducibility of the measurements. The absorbance of the solutions, contained in $1 \mathrm{~cm} \times 1 \mathrm{~cm}$ quartz cells, at $266 \mathrm{~nm}$ was $0.7 \pm 0.1$.

Steady-state absorption spectra were recorded with a Perkin-Elmer Lamda 900 spectrophotometer placed in an air-conditioned room whose temperature was maintained at 23 $\pm 1^{\circ} \mathrm{C}$. The temperature of the solution was controlled by a Huber CC3 apparatus with a precision of $\pm 0.1^{\circ} \mathrm{C}$. 
Irradiations were carried out in a Fluorolog-3 spectrofluorometer. The monochromator bandwidth was $4.7 \mathrm{~nm}$. In order to avoid the formation of high local concentration of photoproducts, solutions were mildly stirred by a magnetic stirrer. During the irradiation the temperature was kept at $23 \pm 1^{\circ} \mathrm{C}$ using a LAUDA ECOLINE 003 apparatus.

The maximum molar absorption coefficient $\varepsilon_{\max }$ of $(\mathrm{dA})_{20} \cdot(\mathrm{dT})_{20}\left(6700 \mathrm{M}^{-1} \mathrm{~cm}^{-1}\right.$ per base) was derived from that of poly(dA) poly(dT) in phosphate buffer $\left(6100 \mathrm{M}^{-1} \mathrm{~cm}^{-1}\right){ }^{19}$ and by comparing the melting curves of the two duplexes (cf. supporting information in reference 20). The $\varepsilon_{\max }$ of $(\mathrm{dT})_{20}$ was taken identical to that of poly(dT) $\left(8700 \mathrm{M}^{-1} \mathrm{~cm}^{-1} \text { per base }\right)^{19}$ because both strands undergo the same very weak temperature dependence (Fig. 2). Errors in $\Delta \varepsilon$ are smaller than $5 \%$.

Figure 2

Content in UV-induced thymine photoproducts was determined by high performance liquid chromatography (HPLC) associated to tandem mass spectrometry. ${ }^{21}$ Briefly, $10 \mu 1$ of irradiated solution was diluted to $50 \mu 1$ in water. Oligonucleotides were enzymatically hydrolyzed in order to release unmodified bases as nucleosides and photoproducts as dinucleoside monophosphates. Hydrolysis involved a first $2 \mathrm{~h}$ incubation $\left(37^{\circ} \mathrm{C}\right)$ step at $\mathrm{pH} 6$ with phosphodiesterase II, DNase II and Nuclease P1. Then, pH was adjusted to 8 and a second $2 \mathrm{~h}$ incubation $\left(37^{\circ} \mathrm{C}\right)$ was carried out in the presence of phosphodiesterase $\mathrm{I}$ and alkaline phosphatase. The resulting solution was injected onto a HPLC system (Agilent series 1100 ) equipped with a $150 \times 2 \mathrm{~mm}$ octadecylsilyl silica gel column (particle size: $3 \mu \mathrm{m}$ ). The mobile phase was a gradient of acetonitrile in $2 \mathrm{mM}$ TEAA. The eluent was then directed towards a tandem mass spectrometer (API 3000, Sciex-Applied Biosystems). Negative electrospray ionization was used. Detection was carried out in the multiple reaction monitoring mode using specific fragmentations for the thymine dimeric photoproducts (545- 
432 and 545-447 for the (6-4) adducts and the CPDs, respectively). External calibration using authentic standards was used for both analytes.

\section{Results and Discussion}

The various thymine dimers detected by mass spectrometry analysis following UV irradiation of $(\mathrm{dA})_{20} \cdot(\mathrm{dT})_{20}$ or $(\mathrm{dT})_{20}$ are shown in Figure 3 . The yield of cis,syn CPDs in irradiated solutions of $(\mathrm{dA})_{20} \cdot(\mathrm{dT})_{20}$ was 18 times higher than that of (6-4) adducts and at least 200 times higher than that of trans, syn CPDs since the latter photoproduct was not detectable. Consequently, it is reasonable to assume that the observed changes in the absorption spectra are due solely to cis,syn CPDs. We stress that the above mentioned ratios of photoproducts are similar to those reported for natural $\mathrm{DNA}^{22}$ suggesting that edge effects do not play a crucial role in the photoreactivity of $(\mathrm{dA})_{20} \cdot(\mathrm{dT})_{20}$. Less than $40 \%$ of the helices contained a thymine dimer; melting curves of irradiated solutions did not differ substantially from those of non-irradiated ones (Figure 2).

Figure 3

The damaged region spectra of the double and single strands, normalized per thymine which reacted, are compared in Figure. 4. The spectrum of $(\mathrm{dA})_{20}(\mathrm{dT})_{20}$ reflects two antagonistic effects: conversion of thymines to dimers leading to a loss of absorption and local denaturation leading to an increase in absorption. The negative band characterizing the spectrum of $(\mathrm{dT})_{20}$ is more intense than that of the duplex $(\mathrm{dA})_{20}(\mathrm{dT})_{20}$ because denaturation does not occur for the single strand. The maximum change in the molar absorption coefficient $\Delta \varepsilon$ is $7500 \pm 300$ and $3000 \pm 300 \mathrm{M}^{-1} \mathrm{~cm}^{-1}$, respectively for the single and the double strand. It is worth-noticing that the two damaged region spectra in Figure. 4 do not differ only in the values of $\Delta \varepsilon_{\min }$ but also in the position of the bands. For the single strand, the minimum is located at $266 \mathrm{~nm}$, which corresponds to the position of the maximum of the UV spectrum 
recorded for non-irradiated solutions. In contrast, in the case of the double strand, the minimum $(271 \mathrm{~nm})$ is shifted by $12 \mathrm{~nm}$ with respect to the maximum of the UV spectrum recorded for non-irradiated solutions $(259 \mathrm{~nm})$.

Figure 4

It may be considered that the variation of the UV absorption spectrum following irradiation of $(\mathrm{dT})_{20}$ is only due to the loss of two reacted thymines. Therefore, the difference between the damaged region spectra of $(\mathrm{dA})_{20} \cdot(\mathrm{dT})_{20}$ and $(\mathrm{dT})_{20}$ corresponds to the structural changes induced by the presence of the CPD within the duplex on the neighboring bases and can be considered as a "damage denaturation spectrum". Figure 5 reveals that the maximum absorption change due to damage denaturation per thymine reacted is about $50 \%$ higher than that induced per base by thermal denaturation.

\section{Figure 5}

The physical background underlying our observations is the existence of excited charge transfer states among different bases. In general, such excited states appearing in organized molecular systems are known to provoke important changes in the oscillator strength, either hypochromism or hyperchromism. ${ }^{23}$ They arise from orbital overlap interactions between different chromophores and they are very sensitive to their relative orientation. ${ }^{23}$ Quite recently, calculations performed by quantum chemistry methods for DNA dimers, base pairs, stacked base pairs and small oligomers have tackled precisely the role of such states in the DNA hypochromism. ${ }^{24-26}$

Disruption of thymine stacking was shown to occur in CPD containing duplexes. ${ }^{5}$ Destacking of thymines should destroy excited charge transfer states among these bases. However, such an effect cannot account for the spectral changes observed in the present work for the following reasons. First, time-resolved studies carried out with femtosecond resolution 
reported that CPD formation in thymine oligomers is ultrafast and involves prestacked thymine pairs. ${ }^{27,28}$ Despite such a partial stacking, heating of $(\mathrm{dT})_{20}$ gives rise to weak but noticeable decrease in $\Delta \varepsilon$ (Fig. 6), suggesting that thymine-thymine charge transfer states give rise to hyperchromism. In contrast, thermal denaturation of $(\mathrm{dA})_{20}$ results to an increase in $\Delta \varepsilon$, in agreement with the hypochromism related to adenine-adenine charge transfer states rationalized by quantum chemical calculations. ${ }^{25}$ Furthermore, the similarity between the damage denaturation spectrum of $(\mathrm{dA})_{20}(\mathrm{dT})_{20}$ and that of thermal denaturation of $(\mathrm{dA})_{20}$, both peaking around $262 \mathrm{~nm}$ (Fig. 6), pleads for local melting on the adenine strand. Finally, the important spectral shift between the damaged denaturation spectra of $(\mathrm{dA})_{20}(\mathrm{dT})_{20}$ and $(\mathrm{dT})_{20}$ (Fig. 4) points out that the nature of the "UV-eliminated" charge transfer transitions is different for the double and the single strand. On these grounds, denaturation induced by one $\mathrm{CPD}$ in $(\mathrm{dA})_{20}(\mathrm{dT})_{20}$ is equivalent to melting of three adenines. These structural changes are compatible with a flipping-out process (Fig. 1).

In conclusion, the use of a new approach based on UV spectroscopy and mass spectrometry and taking into account recent experimental and theoretical developments on the DNA excited states, allowed us to evidence local melting of the adenines located on the opposite strand with respect to the CPD. The feasibility of our approach was demonstrated in the case of a specific sequence known as A-tracts whose bending due to the presence of a CPD was studied by electrophoresis. ${ }^{3}$ We have chosen this sequence because its investigation involved oligomers for which a large number of data on their excited states are available in the literature. We hope that this work will stimulate further theoretical developments aiming at the detailed description of various base sequences including orbital overlap and, ultimately, bring a deeper understanding of the UV induced structural changes. 
Acknowledgements. This work was supported by the French Agency for Research : project number: PCV07_194999

Keywords: Photochemistry, Optical spectroscopy, DNA damage, Cyclobutanes, UV damage repair 


\section{References}

(1) Melnikova, V. O.; Ananthaswamy, H. N. Mutat Res 2005, 571, 91.

(2) Cadet, J.; Sage, E.; Douki, T. Mutat Res 2005, 571, 91.

(3) Wang, C.-I.; Taylor, J. S. Proc. Natl. Acad. Sci. USA 1991, 88, 9072.

(4) Spector, T. I.; Cheatham, T. E.; Kollman, P. A. J. Am. Chem. Soc. 1997, 119, 7095 .

(5) McAteer, K.; Jing, Y.; Kao, J.; Taylor, J.-S.; Kennedy, M. A. J Mol Biol 1998, 282,1013

(6) Park, C. J.; Lee, J. H.; Choi, B. S. Photochem. Photobiol. 2007, 83, 187.

(7) Miaskiewicz, K.; Miller, J.; Cooney, M.; Osman, R. J. Am. Chem. Soc. 1996, $118,9156$.

(8) Mizukoshi, T.; Kodama, T. S.; Fujiwara, Y.; Furuno, T.; Nakanishi, M.; Iwai, S. Nucleic Acids Res. 2001, 29, 4948.

(9) Lukin, M.; de los Santos, C. Chem. Rev. 2006, 106, 607.

(10) Barone, F.; Bonincontro, A.; Mazzei, F.; Minoprio, A.; Pedone, F. Photochem. Photobiol. 1995, 61, 61 .

(11) Markovitsi, D.; Talbot, F.; Gustavsson, T.; Onidas, D.; Lazzarotto, E.; Marguet, S. Nature 2006, 441, E7.

(12) Markovitsi, D.; Sharonov, A.; Onidas, D.; Gustavsson, T. ChemPhysChem 2003, 3, 303

(13) Onidas, D.; Gustavsson, T.; Lazzarotto, E.; Markovitsi, D. J. Phys. Chem. B 2007, 111, 9644 .

(14) Crespo-Hernández, C. E.; Cohen, B.; Kohler, B. Nature 2005, 436, 1141.

(15) Buchvarov, I.; Wang, Q.; Raytchev, M.; Trifonov, A.; Fiebig, T. Proc. Natl. Acad. Sci. USA 2007, 104, 4794.

(16) Santoro, F.; Barone, V.; Improta, R. ChemPhysChem 2008, 9, 2531.

(17) Mouret, S.; Baudouin, C.; Charveron, M.; Favier, A.; Cadet, J.; Douki, T. Proc. Natl. Acad. Sci. USA 2006, 103, 13765.

(18) Marguet, S.; Markovitsi, D. J. Am. Chem. Soc. 2005, 127, 5780.

(19) Riley, M.; Maling, B.; Chamberling, M. J. J Mol Biol 1966, 20, 359

(20) Markovitsi, D.; Onidas, D.; Gustavsson, T.; Talbot, F.; Lazzarotto, E. J. Am. Chem. Soc. 2005, 127, 17130.

(21) Douki, T.; Court, M.; Sauvaigo, S.; Oden, F.; Cadet, J. J. Biol. Chem. 2000, 275,11678

(22) Douki, T. J. Photochem. Photobiol B: Biology 2006, 82, 45.

(23) Scholes, G. D.; Ghiggino, K. P. J. Phys. Chem. 1994, 98, 4580.

(24) Starikov, E. B. Modern Phys. Lett. B 2004, 18, 825.

(25) Santoro, F.; Barone, V.; Improta, R. Proc. Natl. Acad. Sci. USA 2007, 104, 9931.

(26) Santoro, F.; Barone, V.; Improta, R. ChemPhysChem 2008, 9, 2531

(27) Schreier, W. J.; Schrader, T. B.; Koller, F. O.; Gilch, P.; Crespo-Hernades, C.; Swaminathan, V. N.; Carell, T.; Zinth, W.; Kohler, B. Science 2007, 315, 625.

(28) Schreier, W. J.; Kubon, J.; Regner, N.; Haiser, K.; Schrader, T. E.; Zinth, W.; Clivio, P.; Gilch, P. J. Am. Chem. Soc. 2009, DOI: 10.1021/ja900436t. 


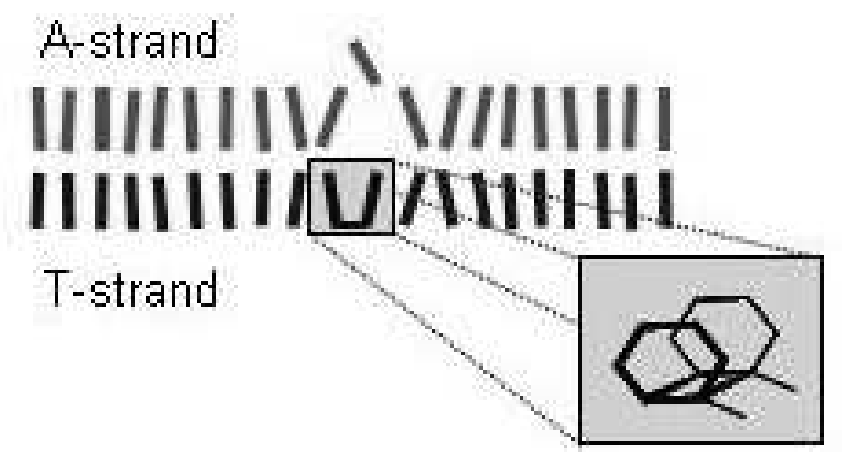

Figure 1. Schematic representation of the duplex $(\mathrm{dA})_{20} \cdot(\mathrm{dT})_{20}$ containing a CPD and a flipped-out adenine. 


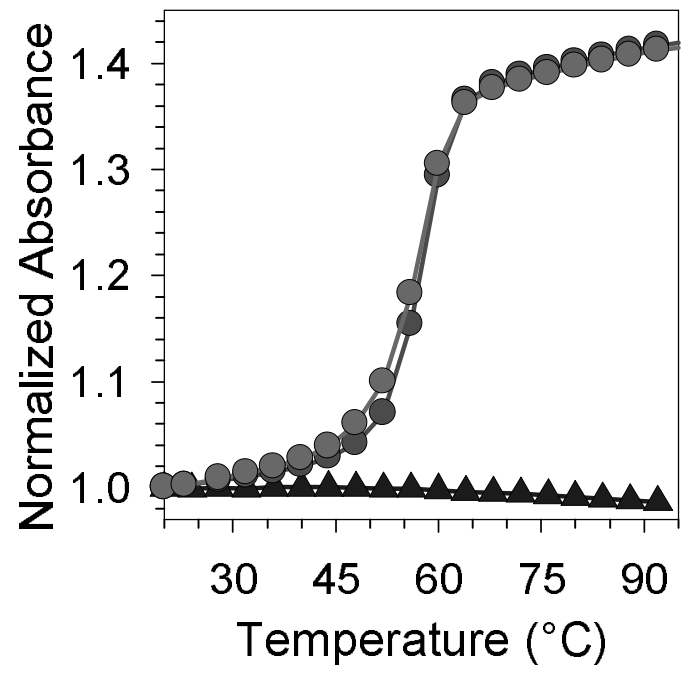

Figure 2. Melting curves obtained at $260 \mathrm{~nm}$ for $(\mathrm{dA})_{20} \cdot(\mathrm{dT})_{20}$ before (green) and after (pink) irradiation and for non-irradiated $(\mathrm{dT})_{20}$ (blue). 


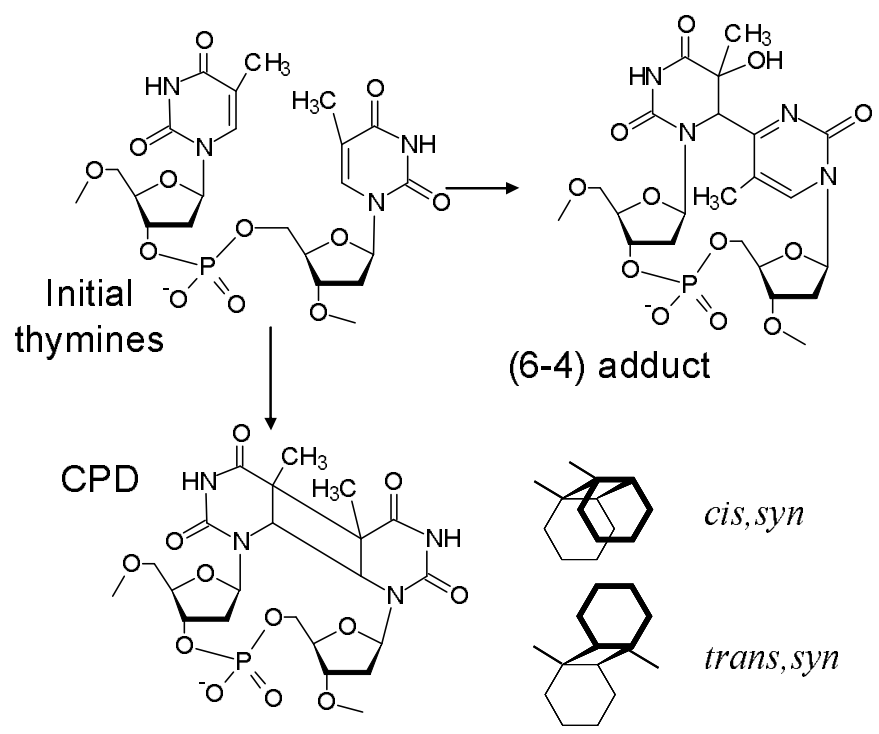

Figure 3. Schematic representation of the cis,syn and trans, syn cyclobutane dimers (CPDs) and the (6-4) photo-adducts. 


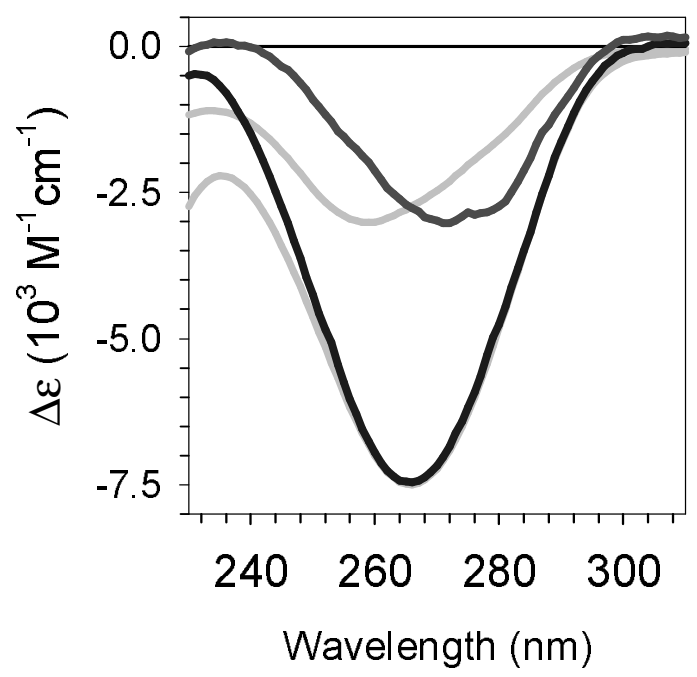

Figure 4. Damaged region absorption spectra of $(\mathrm{dA})_{20} .(\mathrm{dT})_{20}$ (green) and $(\mathrm{dT})_{20}$ (blue), defined as the difference between the spectra recorded after and before irradiation; changes in the molar absorption coefficient $\Delta \varepsilon$ are given per thymine converted to dimer. The inverse of the absorption spectra, normalized to the corresponding damaged region spectra, are shown in grey. 


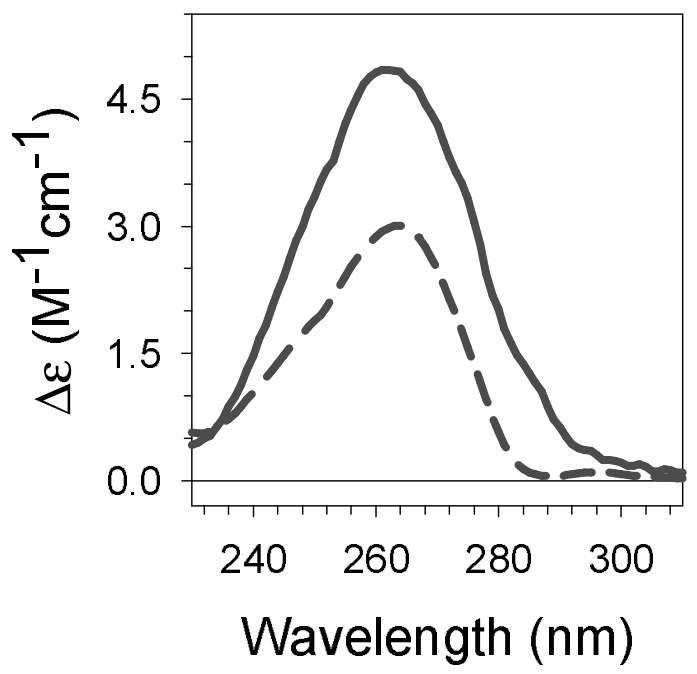

Figure 5. Comparison between the changes induced in the absorption spectrum of $(\mathrm{dA})_{20} \cdot(\mathrm{dT})_{20}$ by CPD formation (damage denaturation spectra: red solid line) and by heating (thermal denaturation spectra: green dashed line). The damage denaturation spectrum is the difference between the green and blue spectra in Figure 4. Thermal denaturation spectra were obtained by subtraction of the spectrum recorded at $23^{\circ} \mathrm{C}$ from that obtained at $92^{\circ} \mathrm{C} ; \Delta \varepsilon$ is given per base. 


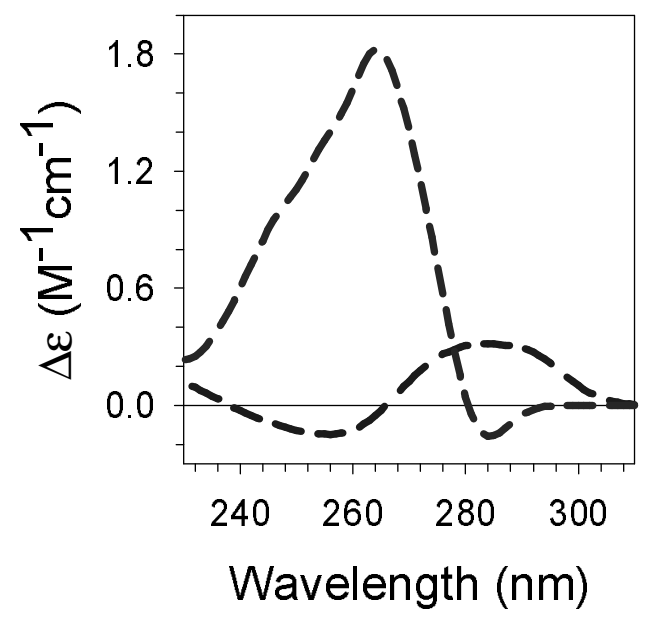

Figure 6. Thermal denaturation spectra of $\mathrm{d}\left(\mathrm{A}_{20}\right)$ (dark red) and $\mathrm{d}\left(\mathrm{T}_{20}\right)$ (blue) obtained by subtraction of the spectrum recorded at $23^{\circ} \mathrm{C}$ from that obtained at $92^{\circ} \mathrm{C} ; \Delta \varepsilon$ is given per base. 